\title{
Misoprostol alone is effective for mid-trimester abortion
}

\author{
Saha $\mathbf{R}^{1}$, Karki $\mathbf{C}^{2}$ \\ 'Rachana Saha, Associate Professor, ${ }^{2}$ Chanda Karki, Professor, Department of Obstetrics and Gynaecology, \\ Kathmandu Medical College Teaching Hospital, Kathmandu, Nepal
}

\section{Abstract:}

Background: The use of prostaglandins has substantially reduced the risk related with mid- trimester abortions. Misoprostol is available in many countries worldwide and is advantageous from the rest of prostaglandin as it is inexpensive, thermo and light stable. It is easy to use and is cheap. It can be used by different routes. Misoprostol has route dependent pharmaco-kinetic profile with best absorption following vaginal administration.

Objective: To find efficacy and safety of intra-vaginal Misoprostol for mid- trimester abortion.

Methods: A hospital based prospective study was carried out at Kathmandu Medical College Teaching Hospital from $1^{\text {st }}$ Jan 2009 to $31^{\text {st }}$ Dec 2010.

A total of 50 cases of mid- trimester termination of pregnancy were analyzed in that period using intra-vaginal Misoprostol 400 microgram every 12 hours till a maximum of 48 hours.

Results: The most common indication for undergoing mid trimester abortion was missed abortion (56\%) followed by congenital abnormalities (22\%). Most of the women were married (98\%). The mean age of the women was $26.21 \pm 5.8$ years (Mean \pm SD). The mean gravidity was $2.63 \pm 1.76$. Mean gestational was $19.60 \pm 3.937$ weeks. The success was defined if Misoprostol was able to induce abortion. Complete abortion was defined if fetus and placenta was expelled completely and was not resorted further to either medical or surgical means. The success rate was $96 \%$. The complete abortion rate was $86 \%$. The mean induction abortion interval was $13.067 \pm 6.21$ hours. Mean dose of misoprostol was $616.667 \pm 285.34$ microgram. The most common side effect was fever with chills and rigor.

Conclusion: Intra-vaginal misoprostol is safe, effective, cheap and easily available method for second trimester termination of pregnancy.

Key words: Abortion, Intra-vaginal misoprostol, Mid -trimester

\section{INTRODUCTION}

$\mathrm{T}$ ermination of pregnancy during mid- trimester is allowed according to the Nepali law only for strict medical reasons. Such reasons include severe fetal anomalies, incompatible with life, chromosomal abnormalities, intra-uterine fetal death, rape up to eighteen weeks of pregnancy and any time during pregnancy if continuation of pregnancy is detrimental to the health of mother ${ }^{1}$.

Currently the most widely used methods of terminating pregnancy in the mid trimester are the vaginal administration of ProstaglandinE $E_{2}$ gel, high dose of Oxytocin, and mechanical dilators like Foley catheter.

Address for correspondence

Dr. Rachana Saha

Associate Professor

Department of obstetrics and Gynaecology

Kathmandu Medical College Teaching Hospital

E-mail: rachana_saha@yahoo.com
Surgical methods include dilation and evacuation of uterus and hysterotomy which requires skilled gynaecologist $2,3,4,6,7$. Since surgical termination of pregnancy has been proved to be high risk for women's health ${ }^{2-4}$, a lot of research is being conducted for safe medical ways of termination. The use of prostaglandins may substantially reduce the risk related with surgical procedures. Misoprostol is available in many countries worldwide and has advantages over the rest of the prostaglandins as it is inexpensive, thermo and light stable and has shelf life of several years even in tropical conditions and is easy to use. Its action upon the contractility of myometrium is extensive and is very efficient in dilating the cervix. It can be used alone or with combination of Mifepristone. For regimens with Mifepristone the doses of Misoprostol required are less but Mifepristone is costly and not available easily ${ }^{2-9}$. The present study had been undertaken to assess the efficacy and safety of vaginal Misoprostol in induction of second trimester abortion. 


\section{METHODS}

A hospital based prospective interventional study was conducted at Kathmandu medical college for period of $1^{\text {st }}$ January 2009 to $31^{\text {st }}$ December 2010 in department of Obstetrics and Gynaecology. Kathmandu medical college teaching hospital has been recognized for providing mid-trimester abortion services in the country since year 2008 and is recognized as training center since 2009 , by both dilatation and evacuation as well as induction of abortion with Mifepristone and Misoprostol.

A total of 50 patients who had indication for undergoing mid trimester abortion were included in the study. The period of gestation was from 13-24 weeks of pregnancy. The pregnant women who had known contraindication to prostaglandins were excluded from the study. At the time of admission detailed history, physical examination was carried out. The gestational age was determined by menstrual history, pelvic examination and confirmed by ultrasound if necessary. Routine investigation included haemogram and blood group. Special investigation was done if required. An informed consent was obtained after counseling regarding the procedure advantages, disadvantage and possible side effects. After admission the women received 400 microgram Misoprostol vaginally, the dose and route of administration was repeated 12 hourly till 48 hours. Patient received analgesic, prophylactic anti-biotics and antipyretic as needed. Maternal pulse, blood pressure, temperature was recorded every 4 hours. Time of onset of contraction, bleeding and expulsion of products of conception including placenta and membrane were recorded. Side effects of the drug were also recorded. Procedure related complications like uterine rupture, cervical tear and laceration was recorded. After delivery of the fetus, all patients received 10 units of Oxytocin in $500 \mathrm{ml}$ of ringer lactate. If abortion was found to be incomplete or failed, surgical intervention was done. Postabortal curettage was performed at the discretion of the physician, if the placenta was not delivered spontaneously after two hours of the delivery of the fetus. The induction was considered to be failed if the woman remained undelivered after more than 48 hours and was resorted to other methods of abortion. Patients were kept under observation for 24 hour and discharged with the advice to come for follow up after two weeks or earlier if necessary. The induction abortion interval was defined as interval between the time of administration of first dose of Misoprostol to the time when fetus was aborted. Success of the procedure was defined if Misoprostol was able to induce abortion. Complete abortion was defined if fetus and placenta was expelled completely without resorting to further surgical or medical means.

\section{RESULT}

A total of 50 patients were included in the study. The most common indication for undergoing mid trimester abortion was missed abortion (56\%) followed by congenital abnormalities ( $22 \%$ ). Most of the women were married (98\%). The mean age of the women was (Mean \pm SD) $26.21 \pm-5.8$ years. The mean gravidity was $2.63 \pm 1.76$. Mean gestational age of the pregnancy undergoing mid-trimester abortion was $19.60 \pm 3.937$ weeks.

The success rate of the procedure after 48 hours was $96 \%(48 / 50)$ cases. Two cases were of failed induction. These two cases were resorted to a combination intra cervical foleys catheter and high dose of oxytocin. There were five cases (10\%) of scanty retained placental tissue and this case underwent manual vacuum aspiration. There was no case of complete retained placenta.

The mean induction abortion interval was $13.067 \pm 6.21$ hours with minimum of three hours and maximum of 28 hours. The success rate at 24 hours was $88 \%$. The side effects of Misoprostol like chills, rigor, and fever were noted in $10 \%(5 / 50)$ cases. $2 \%$ (1) case reported diarrhoea. Though blood loss was visual estimate, it was minimal. None of the patient required blood transfusion.

Table 1 : INDICATIONS OF MID-TRIMESTER ABORTION $(\mathbf{n = 5 0 )}$

\begin{tabular}{lc}
\hline Indications of abortion & Number of patients \\
\hline Missed abortion & 28 \\
\hline Congenital abnormalities & 11 \\
\hline Severe PET & 4 \\
\hline Failed early trimester abortion & 4 \\
\hline Heart disease with PPROM & 1 \\
\hline Acute renal failure with Pyelonephritis & 1 \\
\hline Rape & 1 \\
\hline Total & $\mathbf{5 0}$ \\
\hline
\end{tabular}


Table 2: INDUCTION ABORTION INTERVAL $(\mathbf{n = 5 0 )}$

\begin{tabular}{|c|c|c|c|}
\hline $\begin{array}{l}\text { Induction abortion interval } \\
\text { (IAI) (hours) }\end{array}$ & Number of cases & Percentage & $\begin{array}{c}\text { Cumulative abortion rate } \\
\text { (\%) }\end{array}$ \\
\hline$<6$ & 2 & 4 & 4 \\
\hline $6-12$ & 24 & 48 & 52 \\
\hline $13-18$ & 12 & 24 & 76 \\
\hline $19-24$ & 6 & 12 & 88 \\
\hline$>24$ & 4 & 8 & 96 \\
\hline
\end{tabular}

*Mean induction abortion interval (Mean \pm SD): $13.067 \pm 6.21 \mathrm{hrs}$

*Mean dose of misoprostol required (Mean \pm SD): $616.667 \pm 285.34$ microgram

\section{DISCUSSION}

A variety of medical and surgical techniques have been used to induce uterine evacuation in the second trimester abortion. Despite extensive research comparing these methods to date there is no single method identified to be best among others. There is still a need to find out a method which is cost effective, free of side-effects and complications. Medical abortion besides requiring less skill is also advantageous with regard of evaluation of fetus and placenta in cases of fetus malformation which would help in future research practice and further evaluate subsequent recurrence risk.

Medical methods of inducing second trimester abortion during last decade has become safe and more accessible. The combination of Mifepristone and Misoprostol is now an established and highly effective method for termination but Mifepristone is costly and not available easily. Misoprostol,a uterotonic drug can be administered by different routes. In the study conducted by khan et $\mathrm{al}^{8}$, Misoprostol had route dependent pharmocokinetic profile with best absorption following vaginal administration.

In the present study 400 microgram of Misoprostol was administered vaginally, every 12 hours,for 48 hours. The success rate was $96 \%$. Similar and comparable results of $91.8 \%$ was reported by Eisheikh et $\mathrm{al}^{2}$. In their study they used both oral and vaginal route. $99.26 \%$ success rate was reported by Nagaria et $\mathrm{al}^{3}$ in their study where Misoprostol was used by vaginal route that is 600 microgram followed by 400 microgram for 24 hours. $89 \%$ success rate was reported by Jain et $\mathrm{al}^{4}$ in their comparative study of Prostaglandin $\mathrm{E}_{2}$ and ProstaglandinE $\mathrm{E}_{1}$. They used 200 microgram of Misoprostol intra-vaginally every 12 hours. Azlin et $\mathrm{al}^{6}$ reported success rate of $92.6 \%$ with dose of 200 microgram Misoprostol intra- vaginally every 12 hours. The overall success rate of Misoprostol is 71-100\% (Bugalho et al as cited in Azlin et $\mathrm{al}^{6}$ ). The mean induction abortion interval was 13.067 hours \pm 6.21 hours in the present study. The mean IAI was $9.71 \pm 4.2$ hours by Eisheikh et $\mathrm{al}^{2}$. Similarly Nagaria et $\mathrm{al}^{3}$ reported 12.27 \pm 5.71 hours, 12 hours by Jain et $\mathrm{al}^{4}$ and $19.2 \pm 14.7$ hours by Azlin et $\mathrm{al}^{6}$. The mean dose of misoprostol was $660.667 \pm 285.3$ microgram in the present study. This was quite less compared to Nagaria et $\mathrm{al}^{3}$ of $1638.57 \pm 322.67$ microgram. The dose reported by Azlin6 et al was much less $400 \pm 100$ microgram. $96.6 \%$ success rate was noted by Shah $^{9}$ et al in their study of 400 microgram of Misoprostol followed by 200 microgram vaginally every 4 hours. Mean induction abortion interval was $9.43 \pm 2.03$ hours. The dose of Misoprostol was $666 \pm 31.5$ microgram.

From above observation it seems that dose, route of administration and proper interval of dosing is required. The complete abortion rate was $86 \%$ which is comparable to other studies. The blood loss was minimal and did not require blood transfusion similar to Nagaria et al $^{3}$. Sideeffects were minimal and only required symptomatic treatment. Fever with chills and rigor was the most common side effect similar r,3,4,6 $^{2}$ o other studies.

\section{CONCLUSION}

Intra-vaginal Misoprostol 400 microgram for midtrimester pregnancy termination is very effective, safe and free from any serious side effect.

\section{ACKNOWLEDGEMENT}

We are thankful to the Department of Obstetrics and Gynaecology of Kathmandu Medical College Teaching Hospital for helping us in carrying out this research project. And we are also thankful to the patients without whom this study would not have been possible. 


\section{REFERENCES}

1. National Safe Abortion Policy of Nepal 2003. Kathmandu, Nepal: Ministry of Health and Population, Department of Health Services;2003.

2. Eisheikh A, Antsakilis A, Mesogitis S, Panatoniou N, Rodolakis A, Vogas $E$, et al. Use of Misoprostol for the termination of second trimester pregnancies. Arch Gynaecol Obstet. 2001;265:204--6.

3. Nagaria T, Sirmor N. Intra-vaginal misoprostol for termination of second trimester pregnancy. J Obstet Gynecol India. 2007;57(5):435-8.

4. Jain KJ, Mishell DR. A Comparison of Intra-vaginal Misoprostol with prostaglandin $E_{2}$ for termination of Second trimester pregnancy. New Engl J Med. Aug 1994;331(5):290-3.

5. Dickinson J E. Misoprostol for Second Trimester pregnancy termination in women with prior Caesarean delivery. Obstet Gynaecol.2005;105:352-6

6. Azlin NIM, Abdullah HSNA, Rashid MR, Jamil MA. Misoprostol (alone) in $2^{\text {nd }}$ trimester terminations of pregnancy. As effective as Gemeprost? J Obstet Gynecol. Aug 2006;26(6):546-9

7. Lalit kumar S, Bygdeman M, Danielsson KG. Mid trimester induced abortion: a review. Hum Reprod Update. Oct 2006;1-16.

8. Khan RU,Refaey H, Sharma S et al. Oral,Rectal and Vaginal pharmacokinetics of Misoprostol. Obstet Gynaecol. 2004;103:866-70.

9. Shah SR,Tripathi JB, Suthar HD, Modi KJ, Astik $\mathrm{JK}$, Bhuria DJ. Role of vaginal misoprostol in $2^{\text {nd }}$ trimester termination of pregnancy. J Obstet Gynecol India. 2010 Mar-Apr;60:146-148. 